\title{
Study on the Cooperation Mechanism of Transboundary Water Pollution Control in China from the Perspective of Network Governance
}

\author{
Chu Yijing ${ }^{1}$, Wang Jue ${ }^{2}$ \\ Wuhan Technical College of Communications, Economic Management Academy
}

\begin{abstract}
Transboundary water pollution affects the sustainable socio-economic development in the region.Based on the current social governance tone of co-governance and sharing and the complexity of water pollution, the governance of transboundary water pollution is not just the "one-man show" of the government, but also included in the main body of private enterprise organizations, non-profit environmental organizations and citizens. The multiple subjects included in the network of governance should take into account the goals of ecological effects, social effects and economic effects, and establish cooperation in cross-border water pollution control by establishing good communication channels, coordinating governance activities, strengthening trust and sharing relationships, and handling cultural differences mechanism.Compared with the traditional model of control and governance by a single administrative force, the network cooperative governance of transboundary water pollution is more flexible, autonomous, innovative, public and economical. Its core philosophy is "cross-border cooperation and pollution sharing Governance, effectiveness sharing, multi-win-win situation. "
\end{abstract}

\section{Introduction}

After the reform and opening up, the rapid development of urbanization and industrialization has promoted the advancement of China's economy and society On the other hand, it has also brought tremendous pressure on China's ecological environment. The frequency of ecological disasters and environmental pollution has also increased,Among them, transboundary water pollution incidents have increased in recent years. the importance of environmental governance urgency and regional cooperation and pollution control has become an important issue, and cross-border water pollution control is no exception. This study mainly focuses on cross-border cooperation in water pollution control. Based on the theory of "network governance", it includes governmental subjects and non-governmental subjects to discuss how to build a cooperation mechanism for cross-border water pollution control. This study is not only based on the existing domestic research, but also attempts to propose an innovative cross-border cooperative water pollution control mechanism on the basis of the existing research.

\section{Literature review}

Domestic scholars' researches on China's trans-regional environmental governance and trans-boundary water pollution governance mainly focus on the following aspects: first, the research on governance mode.
According to the categories of governance bodies, some scholars have proposed five specific models of cross-border water pollution control, namely, hierarchical governance model, regional integration model, inter-governmental cooperation model, quasi-market model and social governance model. some scholars proposed a network governance model based on the complexity characteristics of cross-border water pollution. There are also scholars' multi-center governance as a theoretical perspective. From the perspective of roles and responsibilities, taking the environmental governance of the Beijing-Tianjin-Hebei region as a case, the paper proposes a "four-center" regional environmental collaborative governance model based on "government, enterprises, people, and non-government environmental organizations". The second is the analysis of the dilemma and causes of cross-regional environmental governance and water pollution control. Scholars mainly focus on the dimensions of administrative system, legal protection, and characteristics of water pollution control. Third, research on trans-regional environmental governance and local government cooperation. Scholars combine the two to conduct research on the factors, dynamics, and mechanisms of cooperation.Fourth, Fourth, from a theoretical perspective, existing research has been discussed from the perspective of multi-center governance, the perspective of collaborative governance, the perspective of network governance, and the perspective of "trust-agent". 
A general survey of the existing studies on cross-border environmental governance and cross-border water pollution control in China shows that there are relatively many studies on trans-regional environmental governance and local government cooperation, and they tend to form a consensus on "cooperative governance". However, there is still a lack of in-depth discussion on the cooperation mechanism. In terms of governance dilemma, scholars regard the divided administrative system as the main reason, but pay little attention to the participation of non-governmental subjects in cross-border government. In terms of research methods, scholars mainly focus on case analysis and normative analysis.

\section{Theoretical analysis: network governance}

This study uses the concepts and perspectives of "networked governance" to conduct analysis. The "networked governance" model is an alternative to the hierarchical government management system. It is a collection of four public sector forms of development, including third-party government, collaborative government, digital technology and citizen selection. Based on the indivisibility and complexity of transboundary water pollution control, as well as the government's ecological civilization construction and regional development policies, network governance is undoubtedly a sensible rational choice.

\subsection{The connotation of networked governance}

"Networked governance" is proposed by Stephen goldsmith and William d. eggers, and this governance model is a specific discussion of "holistic government". It not only emphasizes the high degree of public-private cooperation, but also means that the government has a strong management ability to the public-private partnership network. That is to say, network governance combines the high-level public-private cooperation characteristics of third-party governments and the strong management ability of collaborative governments, and makes use of information technology to connect the network formed between each other. As a result, citizens have extensive selective rights in the provision of social public services. In short, "network governance is the highest level of cross-border cooperation", which is characterized by integration of synergy, cooperation, technology and service.

\subsection{Key elements of network governance}

The key element of "network governance" is to establish a link to the network, including four important components: first, to establish an effective communication channel, information technology supported by digital technology, face-to-face interactive communication are effective ways to achieve full communication between each other. Second, to coordinate various activities, governance bodies need to coordinate the comprehensive response to emergencies, enhance the visibility of governance operation process, share relevant information of customers and strive to make customers' views consistent.Third, building relationships. In this element, the first is to establish an effective governance structure for the network. Secondly, knowledge sharing among organizations, including external knowledge and tactical knowledge; Finally, trust and cooperation should be established between organizations that have been rivals, because trust is the basic condition of cooperation. The fourth is to deal with cultural differences. The network structure of governance has subjects from different interest representatives, as well as different cultural backgrounds and ideological values. In summary, the governance bodies in the network structure must design diverse ways to establish effective communication channels, coordinate activities among network partners, share information and knowledge, adjust values, coordinate benefit distribution and incentive mechanism, establish trust and cooperation relations and overcome cultural differences as much as possible. The whole network cooperation process contains the spirit of "seeking common ground".

\subsection{Cross-border water pollution control from the perspective of network governance}

The feasibility of transboundary water pollution control from the perspective of network governance lies in that transboundary water pollution control has the characteristics of public goods, which should not only be undertaken by the government. First, on the one hand, once water pollution occurs in a certain region, it will not only affect the administrative region, but also its negative influence may spread to surrounding areas, which is also known as "negative externality effect". Therefore, local governments in different administrative regions have the demand for cooperative governance. On the other hand, private enterprises, non-profit organizations, and citizens as stakeholders also have the responsibility and obligation to join the cross-border water pollution control.Therefore, multi-subjects involved in cross-border water pollution control are the premise of establishing "network governance" relationship. Secondly, in terms of cross-border water pollution control itself, it involves the release and sharing of public opinion information, technical issues of water pollution treatment, people's life safety, etc. These typical characteristics are also consistent with the prominent features of the "network governance" model. Thirdly, in terms of specific cooperation strategies, if good governance of cross-border water pollution is to be achieved, it is necessary to establish trust and cooperative relations among network partners, which need to be realized through effective communication, appropriate coordination, harmonious relations and wide identification, which are exactly in line with the key elements of network governance. 


\section{Cooperation status: cooperation in transboundary water pollution control}

A typical feature of transboundary water pollution is its "transboundary nature". Therefore, stakeholders from different regions need to cooperate to eliminate the harm caused by pollution and establish a long-term cooperation mechanism for water environment management. Judging from the current status of cooperation in cross-border water pollution control in China, achievements and problems coexist.

\subsection{Effective progress}

The most important cooperative treatment of transboundary water pollution is inter-governmental cooperation, or more precisely, the cooperation between local governments, which is based on the leading role of the government in environmental governance. The power and responsibility relationship between the central government and local governments in water pollution control has been gradually straightened out, and some local governments have reached consensus on regional water pollution control and established cooperative relations. after the establishment of a cooperative mechanism for joint pollution control, the three governments have gradually worked together to get rid of the dilemma of "upstream pollution and downstream treatment" and basically realized the pattern of "cost sharing, benefit sharing and cooperative governance" in water environment control.

\subsection{Problems still exist}

The effective treatment of water pollution in Beijing-Tianjin-Hebei region is not a normal phenomenon of cross-border water pollution control in China. It can only be regarded as a typical successful case. As for most regions of the country, transboundary water pollution control is still in an "awkward" situation. In theory, the main body should establish perfect cooperative relations, and some local governments, private enterprises, non-profit organizations and the public also realize the importance of cooperation in pollution control. However, the reality is that the division of the administrative system has made the cooperation relationship difficult to establish; even if it is established, the lack of coordination and supervision mechanism is difficult to guarantee the cooperation performance, and the lack of incentive and compensation mechanism makes the cooperation relationship difficult to maintain for a long time.

\section{Premise of cooperation: necessity and importance of network treatment of transboundary water pollution}

Cross-border water pollution control is a public affair related to social development and public safety. The premise of cooperative treatment is that it has cooperative value. The significance of cross-border water pollution cooperation is manifested in the following three aspects: first, as the object of environmental governance, it is the only way to achieve a good regional environment; Second, as the supply of public goods, the indivisibility of water pollution control makes cooperative treatment a wise choice. Third, a better water environment, as a carrier of citizens' sense of acquisition, endowing people with life safety.

\subsection{Being the object of environmental governance: the only way to achieve good regional development}

\subsection{1. "Treat the environment like life"}

With the rapid development of economic society, China attaches increasing importance to the construction of ecological civilization, emphasizing that "treat the ecological environment like life". The central government's ecological civilization construction, "Green" and "Shared" development concept, regional coordinated development strategy, "Jointly Build, Jointly Govern and Share" social governance pattern and other social development tenor, make cross-border water pollution cooperation undoubtedly become one of the urgent tasks of regional construction and development. It together with air pollution and soil control, constitutes an important part of environmental control and is related to the development of regional natural environment. Therefore, the urgency of transboundary Cross-border water pollution control calls for stakeholder consultation and dialogue and joint governance.

\subsection{2."Clear water and green mountains are like mountains of gold and silver"}

In March 2015, the CPC central committee and the state council issued the document "Opinions on Accelerating the Construction of Ecological Civilization", and the conclusion "Clear Water and Green Mountains are Like Mountains of Gold and Silver" was formally written into the document, and became an important guiding ideology of China's ecological civilization construction. This guiding ideology "profoundly expounds the relationship between man and nature, reveals the dialectical relationship between economic development and environmental protection, and highlights the important concept that protecting the ecological environment is protecting the productive forces and improving the ecological environment is developing the productive forces. Therefore, the government should realize the importance of water environment to national economic construction and balance the relationship between cross-border water pollution control and regional economic development. In addition, from the cost-benefit perspective, cooperation in cross-border water pollution treatment can reduce the treatment cost and "enlarge" the treatment performance, which has important economic significance. 


\subsection{Supply of public goods: indivisibility of water pollution control}

As a kind of supply of public goods beyond administrative boundaries, trans-regional water pollution control is inefficient because of its natural nature. As a public good, the water environment is natural and non-exclusive. First of all, in terms of indivisibility, the government is the primary undertaker of environmental protection and governance, but the government is not the only one. Enterprises related to water pollution, non-profit environmental protection organizations and local residents should all be included in this governance system. As a force to maintain the local environment, non-profit environmental protection organizations play the role of propaganda, mobilization and supervision in environmental governance. Secondly, in terms of the non-exclusivity of the benefits, the natural environment is non-closed, especially in China, where the east, central and south have a dense network of water areas, and the radiation range of a good water environment involves multiple regions. Therefore, as a type of public goods supply, water pollution control has its own characteristics of public goods, which also provides the possibility of cooperative governance.

\subsection{As the carrier of citizens' sense of acquisition: a better water environment endows people with a safe life}

Citizens' sense of acquisition is closely related to the government's ability to provide public services. The sense of citizenship is closely related to the government's public service ability: the government provides a good quality public service, and citizens will have a strong sense of gain; on the contrary, the citizen's sense of identity will be reduced and the sense of gain will be reduced.As an important resource related to people's life stability and safety, water is an indispensable part of people's daily life. Once transboundary water pollution occurs, the affected cities may face economic losses, and the worse result is to cause public panic and endanger social and public safety. Effective treatment is an important way to eliminate the negative effects of water pollution. Therefore, from the social level, the cooperative treatment of transboundary water pollution can effectively guarantee people's life safety.

\section{Cooperation mechanism: a way for stakeholders to jointly build, govern and share}

The core spirit of networked governance is "cross-border cooperation". Network governance mode is introduced in cross-border water pollution control. The most important thing is to establish effective cooperation mechanism after establishing network partnership. According to the key elements of networked governance, the long-term cooperation mechanism should first build effective communication channels among multiple governance bodies, which is equivalent to establishing communication networks and governance structures to connect each other. Secondly, multiple subjects in the governance structure should actively coordinate pollution control activities, including establishing specific cooperation and action strategies, establishing responsibility, incentive and compensation mechanism for coordinated action, etc. Thirdly, it is necessary to establish hard and soft constraints to strengthen the trust and sharing relationship, which is embodied in the improvement of laws and regulations, the establishment of feasible supervision and restraint mechanism, and the strengthening of the ideological identity of collaborators. Finally, cultural differences among different governance bodies must be properly handled and preferences harmonized. To sum up, in transboundary water pollution control, multiple parties link resources through consultation and dialogue on the basis of reaching consensus on goals, with the goal of achieving collaborative governance.

\subsection{Build effective communication channels for diverse governance bodies}

\subsubsection{Collaborative network:set up a special working group on cross-border water pollution control}

According to the network governance model, the integrated network should be determined in the governance process, so it is necessary to determine which subjects should be included in the network. In the process of transboundary water pollution control, local governments at all levels, relevant administrative departments, enterprises and institutions related to water environment construction in administrative regions, non-profit organizations of environmental protection, and all the people in the region should be included in the transboundary water pollution control network. Secondly, among these bodies, the government controls the most environmental protection resources and is the most major undertaker of environmental governance. Therefore, it plays a leading role in network coordination, and the government has the responsibility to lead the establishment of a special working group on water pollution control. The working group should be composed not only of government staff but also of the principal heads of the above-mentioned bodies. Third, there is a relationship of cooperation and equality among the various subjects incorporated into the integrated network. Although the government and its working departments play a leading role, they are in a relationship of consultation and dialogue with other subjects. Finally, after the special working group on transboundary water pollution control, a regular consultation and dialogue mechanism should be established, including convening meetings, signing agreements and collective action.

\subsubsection{Digital connection: establish a network information platform for water pollution control}

At present, informatization is a prominent feature of 
modern society, especially the rapid development of Internet technology, big data technology and internet of things technology, which provides a technical basis for trans-regional governance. Therefore, network information platform for water pollution control should be established in the process of cross-border water pollution control network, including regional water pollution and control data information, water environment construction information, etc. At the same time, a dynamic information update mechanism should be established in this platform to enable network partners to retrieve timely information on the status of cross-regional water pollution control so as to adopt realistic action strategies.

\subsection{Coordinating multi-subject governance activities}

In network governance, coordinating the governance activities of multiple subjects is actually the process of "reaching the goal consensus and linking resources of all parties to cooperate", which is a key part of network governance model. In terms of cross-border water pollution control, multiple parties should reach a consensus on the control objectives, and establish an open and transparent working mechanism, especially an emergency handling mechanism to deal with water pollution emergencies.

\subsubsection{Achieve the consistent goal of transboundary water pollution control}

Joint action by multiple actors must be based on consensus. On transboundary water pollution control, multiple subjects should reach a consensus on the ecological, social and economic effects of water pollution control. Among them, the ecological effect is to realize the harmony between man and nature and promote the sustainable development of water resources. The social effect is that the public interest, especially the people interest, should be fully considered in the process of pollution control. Economic effect refers to the consideration of the cost of water pollution control and the positive impact of successful water pollution control on local economic development. Therefore, in the goal of water pollution control, multiple subjects should seek consensus on ecological effect, social effect and economic effect, and seek the organic unity of the three.

\subsubsection{Establish an open and transparent governance operation mechanism}

The networked governance of transboundary water pollution must establish a specific operational work mechanism to ensure that the governance process is carried out normally. Specifically: First, it is necessary to establish a cooperative governance responsibility mechanism, that is, the responsibilities and obligations of each subject must be clearly defined in text form, and a disciplinary mechanism for default should be established. One of the shortcomings of networked governance is that multiple entities may push each other out and there is a situation of ambiguous responsibility. The second is to form a normalized working mechanism for different types of water pollution. Transboundary water pollution is characterized by suddenness, complexity, and diffusivity ,It is necessary to establish a normalized emergency response mechanism for water pollution emergencies. The third is to establish an incentive mechanism to participate in cooperative governance. A single government supervision method cannot achieve effective governance of transboundary water pollution, and it is necessary to comprehensively use social means to mobilize the enthusiasm of all parties to participate in governance. For enterprises actively participating in water pollution treatment, the government can make preferential policies such as tax reduction and exemption. Fourth, we will establish an interest compensation mechanism. Multi-party participation in cross-regional water pollution control will inevitably result in the loss of interests of one or several parties. However, networked governance emphasizes "cooperation and win-win", and the establishment of benefit compensation mechanism is a necessary means to ensure the continued participation of relevant parties in cooperation.

\subsection{Strengthening the relationship between trust and sharing}

The good trust and sharing relationship among network partners increases the social capital of network structure and promotes the goal consensus among multiple subjects. After the establishment of integrated network, the trust and sharing relationship between subjects must be strengthened through various forms.

\subsubsection{Hard constraints: improve laws and regulations, strengthen policy constraints and establish supervision and evaluation system}

Sound laws and regulations and clear policy documents are the basis for the legitimacy of the transboundary water pollution control process. Therefore, first of all, the central government and local governments should strengthen the regulation of laws and policies on water environmental governance, so that water pollution control can be based on laws. Secondly, within the network structure, an effective monitoring mechanism and performance evaluation system must be established, and each entity should supervise each other to improve governance performance.

\subsubsection{Soft Constraints: Strengthening Ideological Identity}

In strengthening the trust and sharing relationship between network partners, the ideological and conceptual identity within the multi-subject is stronger than the external hard-binding. Therefore, multi-subjects should work together to establish a common culture of integrated networks, unite team strength through propaganda, collaboration, and action, and shape 
organizational spirit, thereby strengthening the ideological and conceptual identity of cross-border water pollution control.

\subsection{Dealing with cultural differences}

The distrust of network partners due to their different cultures and values is a challenge within the network structure."Sometimes it's between private and nonprofit partners, and sometimes it's between government and its partners. government organization has many characteristics, such as political, public and mandatory, private enterprise has a for-profit, result oriented, and public welfare environmental groups often tinged with humanism, There may be distrust between the two because of different values, and even conflicts and contradictions. Therefore, differences in organizational cultural background should be reasonably handled to eliminate conflicts through consultation and dialogue.

\section{Conclusion}

Compared with hierarchical government, collaborative government and third-party government, networked governance mode has advantages such as specialization, innovation, speed and flexibility, and strong autonomy, but it may also face disadvantages such as communication difficulties, conflicts between goals and values, fuzzy responsibility and weak supervision.From the perspective of network governance model, the core idea of trans-regional water pollution governance is "no unilateral action by a local government can solve the trans-boundary water pollution problem, and joint cooperation in various aspects is needed to optimize the resource mix." Therefore, cross-border water pollution control needs to overcome the defects of the network governance model, establish trust and sharing relationship and realize the overall goal of jointly building regional environment, jointly controlling water pollution, and sharing the effectiveness of govern.Multiple subjects of social governance should take the opportunity of transboundary water pollution to cultivate the spirit of social community and realize the sustainable developiment of regional environment in the process of "joint construction, governance and sharing".

\section{Authors}

${ }^{1}$ Chu Yijing, PhD, associate professor, Wuhan Technical College of Communications, Economic Management cademy, E-mail: xiaojing618@126.com

${ }^{2}$ Corresponding Author: Wang Jue, master, lecturer, Wuhan Technical College of Communications, Economic Management cademy. E-mail: bestywang@qq.com

\section{Fund Project:}

The annual project of national social science fund: Mechanism Research of "Co-construction -Co-governance -- Sharing" of Trans-regional Ecological
Environment in the Yangtze River Economic Belt." (16BGL200);

Key project of national social science fund: "Research on Integrated and Integrated Governance Model of Cross-domain Ecological Environment”（18AZD004）

\section{Reference}

1. [US] Stephen Goldsmith, William D. Eggs. (2008)Networked Governance: A New Form of the Public Sector [M]. Sun Yingchun Translated. Beijing: Peking University Press.

2. Cao Yiqing. (2017)Analysis of Government Collaborative Management of Water Pollution Control[J].Journal of Jishou University(Social Science Edition), (3).

3. Jiang Guohua, Liu Wenjun. (2018)Theoretical Interpretation of Xi Jinping's Governance Concept of "Building and Managing Together"[J].Quest, (1).

4. Lang Youxing.( 2017)Towards a Win-Win Situation: China's Environmental Governance and Regional Government Cross-Regional Cooperation [J]. Journal of Ningbo Party School.

5. Li Xingping.(2016)On the role of vertical embedded governance mechanism in river basin transboundary water pollution control[J].Ecology and Economy, (12).

6. Quan Yongbo.The Logical Basis and System Supply of Cross-Regional Governance in Marine Environment[J].Administration Administration of China,2017(11).

7. Wang jinnan. (2017)The theoretical connotation and realization mechanism innovation of "clear water and green mountains are like mountains of gold and silver" Environmental Protection, (11).

8. Wang Hui etc. (2017)The relationship between "clear water and green mountains " and " mountains of gold and silver" [J]. China Rural Economy, (4).

9. Zhao Fengyi,Xiong Minghui.( 2017)The Dilemma and Coping Strategies of Cross-regional Water Pollution Control in China[J].Nanjing Social Sciences, (5). 